\title{
DETERMINATION OF THE OPTIMAL DEPOSITION CONDITIONS OF OXIDE-ZIRCONIUM COATING ON STEELBASE
}

\author{
M. Zh. Zhurinov ${ }^{1}$, V.N. Statsyuk ${ }^{1}$, L.A.Fogel ${ }^{1}$, A. Bold ${ }^{1,}$, \\ A. A.Abrashov ${ }^{2}$ and A. Kostiuk ${ }^{2}$ \\ ${ }^{1}$ D.V. Sokol'skiy Institute of Fuels, Catalysis \& Electrochemistry, Almaty, Kazakhstan \\ ${ }^{2}$ D.I. Mendeleev University of Chemical Technology of Russia, Moscow, Russia \\ *E-mail: b.amangul@inbox.ru
}

\begin{abstract}
In this paper, we developed a process for the deposition of adhesive oxide-zirconium coatings from solutions of hexafluorozirconic acid in the presence of $\mathrm{Co}$ (II) and $\mathrm{Ni}$ (II) ions on a steel base. The optimal conditions for the formation of oxide-zirconium coatings (concentrations of hexafluorozirconic acid, Co (II) and Ni (II) ions, temperature, $\mathrm{pH}$, deposition time, thickness) are determined. The corrosion resistance of the obtained coatings was investigated depending on the change in the process parameters. It is found that the stabilization of the current-free potential and the optimum thickness of the zirconium oxide coating are achieved at close time parameters. The results of corrosion tests are in agreement with the adhesion strength of the obtained oxide-zirconium coatings on iron base in the temperature range $30-40^{\circ} \mathrm{C}$.It is shown that the formed oxide-zirconium coatings satisfy the requirements imposed on adhesion layers for paint coatings.

Keywords: Zirconium oxide coatings, Hexafluorozirconic acid, Cobalt, Nickel, Adhesion, Protective ability.
\end{abstract}

(C) RASĀYAN. All rights reserved

\section{INTRODUCTION}

Corrosion of metals leads to significant damage in the heat-and-power, oil-field, machine-building, and other industries. The fight against this negative phenomenon seems an urgent task, which has both a multifaceted scientific interest and practical importance. Among the ways to protect metal structures from corrosion, various paints and varnishes (LCP), electrochemical electroplating coatings, etc. are the most common. It should be noted that among the known methods, corrosion protection using LCP takes a leading place. Modern technology LCP deposition on metal surfaces requires pre-deposition of adhesion phosphate coatings which greatly exceed the LCP layer without phosphate. ${ }^{1-6}$ However, the process of phosphating and technology for producing phosphate coatings are not environmentally friendly. In recent years, as an alternative to adhesive phosphate layers, nanostructure ceramic adhesive coatings have been increasingly used in world practice. . $^{7-8}$

The advantages of new technologies are their lower energy consumption and manufacturability compared to phosphate processes. Ceramic coatings have high thermal and electrical resistance. The deposition of ceramic adhesive coatings is carried out at room temperature, and they are easy to apply, to form a much smaller sludge and more environmentally friendly. One of the most promising ceramic coatings is nanostructured oxide-zirconium layers containing zirconium $\left(\mathrm{ZrO}_{2}\right){ }^{9-15}$

For deposition of the zirconium oxide coatings to the metal base is necessary to determine optimum conditions of their formation: preliminary processing of the metal substrate, the concentration of initial materials, time, $\mathrm{pH}$, temperature of the solution used and the temperature of coated samples subsequent drying. An important place should be given to the thickness, adhesive strength, corrosion resistance of the obtained coatings.

Rasayan J. Chem., 12(3), 1287-1293(2019)

http://dx.doi.org/10.31788/RJC.2019.1235205

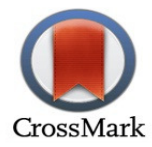


RASĀYAN J. Chem.

Vol. 12 | No. 3 |1287 - 1293| July - September | 2019

\section{EXPERIMENTAL}

\section{Material and Methods}

The reagents sodium sulfate $\mathrm{Na}_{2} \mathrm{SO}_{4}$, hexafluorozirconic acid $\mathrm{H}_{2} \mathrm{ZrF}_{6} 50$ wt\% solution water, nickel nitrate $\mathrm{Ni}\left(\mathrm{NO}_{3}\right)_{2} * 6 \mathrm{H}_{2} \mathrm{O}, \mathrm{CoSO}_{4} * 7 \mathrm{H}_{2} \mathrm{O}$ used in the work had the mark "х.ч" and "oc.ч " distilled water was used to prepare the solutions.

Plates of cold-rolled steel of grade (Art. 08ps) were used as samples. Pretreatment of metal plates was carried out by degreasing in an aqueous alkaline detergent composition with a concentration of 15-20 g / 1 at a temperature of $60-65^{\circ} \mathrm{C}$ for $2-10$ minutes, then the surface of metal plates was cleaned with abrasive material, followed by washing with distilled water.

The deposition of the oxide-zirconium coating was carried out at room temperature with stirring on a rotating unit RDE710 with a rotation speed of $500 \mathrm{rpm}$. Using a $\mathrm{pH}$ meter (И-130), the allowable $\mathrm{pH}$ range of coating formation was established. After coating, the plates were dried at a temperature of $130^{\circ} \mathrm{C}$.

The thickness of the coatings was determined using an SER 800 spectroscopic ellipsometer (manufactured by SENTECH Instruments $\mathrm{GmbH}$ Germany), which makes it possible to accurately measure the thickness and optical characteristics of both monolayer films and multi-layer film structures during deposition. Measurements were performed in the spectral range of light wavelengths 240-1000 nm.

The measure of the current-free potential of the metal substrate during the coating was carried out with respect to $\mathrm{Ag} / \mathrm{AgCI}$ reference electrode by METROM (Switzerland) firm using a potentiostat-galvanostat AUTOLAB (Netherlands).

The resulting coatings were painted with powder paint in the coating chamber, followed by drying at $210^{\circ} \mathrm{C}$ for $10-15$ minutes. Determination of adhesion was performed by the method of normal detachment (fungi method) on a digital adhesiometer PosiTest AT.

For an accelerated assessment of the coatings protective ability a rapid method using the Akimov's reagent - a solution, containing $\mathrm{CuSO}_{4} \cdot 5 \mathrm{H}_{2} \mathrm{O} ; \mathrm{NaCl} ; \mathrm{HCl}$ was used. ${ }^{16}$ According to this method, the corrosion resistance of the oxide-zirconium coating was evaluated by the time (s) of the color change of the control solution drop on the surface of the coating from gray to red-brown. Corrosion tests of adhesive oxide-zirconium coatings with paint were carried out in an Alcott S450iP salt fog chamber in accordance with the international standard ASTM B117. ${ }^{17}$

\section{RESULTS AND DISCUSSION}

Oxide-zirconium coatings were obtained from solutions of hexafluorozirconicacid.InFig.-1 shows the dependence of corrosion resistance of the coating iron sample (according to Akimov's method) on the concentration of hexafluorozirconic acid $\left(\mathrm{H}_{2} \mathrm{ZrF}_{6}\right)$ in the range from 0.5 to $3 \mathrm{~g} / \mathrm{l}$.

According to Fig.-1 the corrosion resistance of zirconium oxide coatings on a steel basis reaches a maximum value in the range of concentrations of $\mathrm{H}_{2} \mathrm{ZrF}_{6}$ from 1.3 to $1.5 \mathrm{~g} / \mathrm{l}$, and at higher concentrations, the corrosion resistance decreases. Obtaining oxide-zirconium coatings becomes possible at a pH of $4.0 \div$ 5.0.At lower $\mathrm{pH}=3.5$, coatings do not form, and at high $\mathrm{pH}>5.5$, the quality of coatings deteriorates. Under these conditions, the coating becomes uneven and unstable and observed copious slogging in the bulk solution.

To form coatings having high corrosion resistance, hexafluorozirconic acid solutions should contain heavy metal ions, which in the absence the depositing layers have a defect on the entire surface of the sample in the form of corrosion. The effect of the Co (II) and Ni (II) ions concentration on the protective ability of the formed oxide-zirconium coatings is shown in Fig.-2.

According to Fig.- 2, the optimal concentrations of Co (II) and Ni (II) ions, at which maximums corrosion resistance of the formed oxide-zirconium coatings is observed, are 0.16 and $0.8 \mathrm{~g} / \mathrm{l}$, respectively. In view of the data obtained for further study were chosen solutions containing 0,8-2,0 г/л $\mathrm{H}_{2} \mathrm{ZrF}_{6},+0,02 г / л \mathrm{Co}^{2+}$ $+0,8$ г/л $\mathrm{Ni}^{2+}$.

To establish the optimal time of oxide-zirconium coatings formation by ellipsometric method (Fig.-3) and measurement of the current-free potential during the coating formation (Fig.-4) was used. 
RASĀYAN J. Chem.

Vol. 12 | No. 3 |1287 - 1293| July - September | 2019

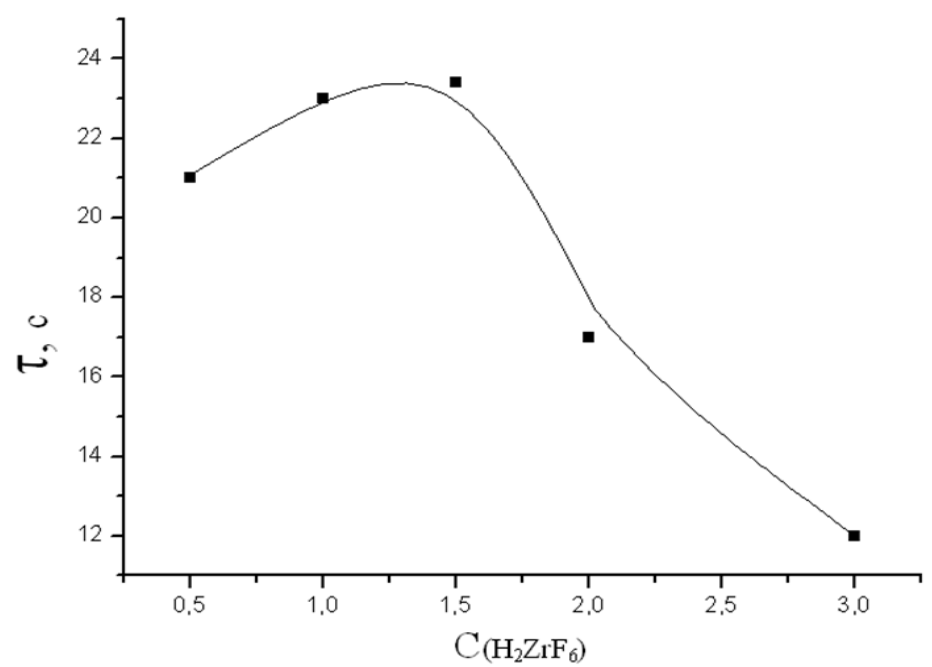

Fig.-1: Effect of Hexafluorozirconic Acid Concentration on the Corrosion Resistance of the Resulting Coatings

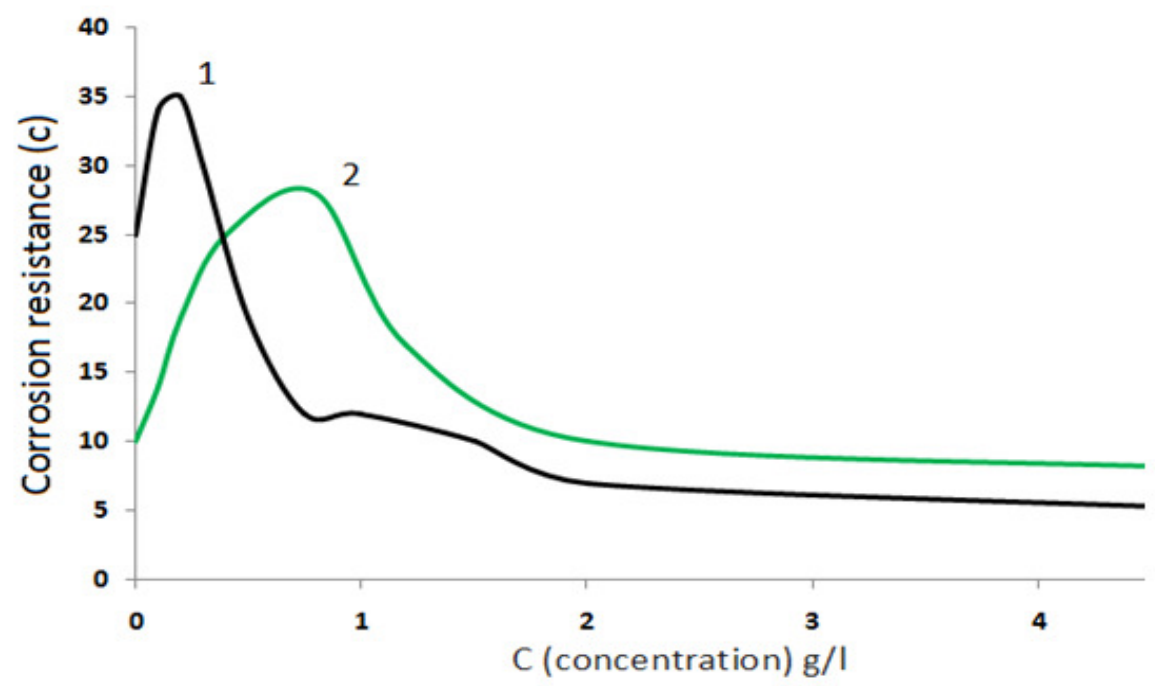

Fig.-2: Effect of Co (II) (1) and Ni (II) (2) Ion Concentration on Corrosion Resistance of Oxide-Zirconium Coatings

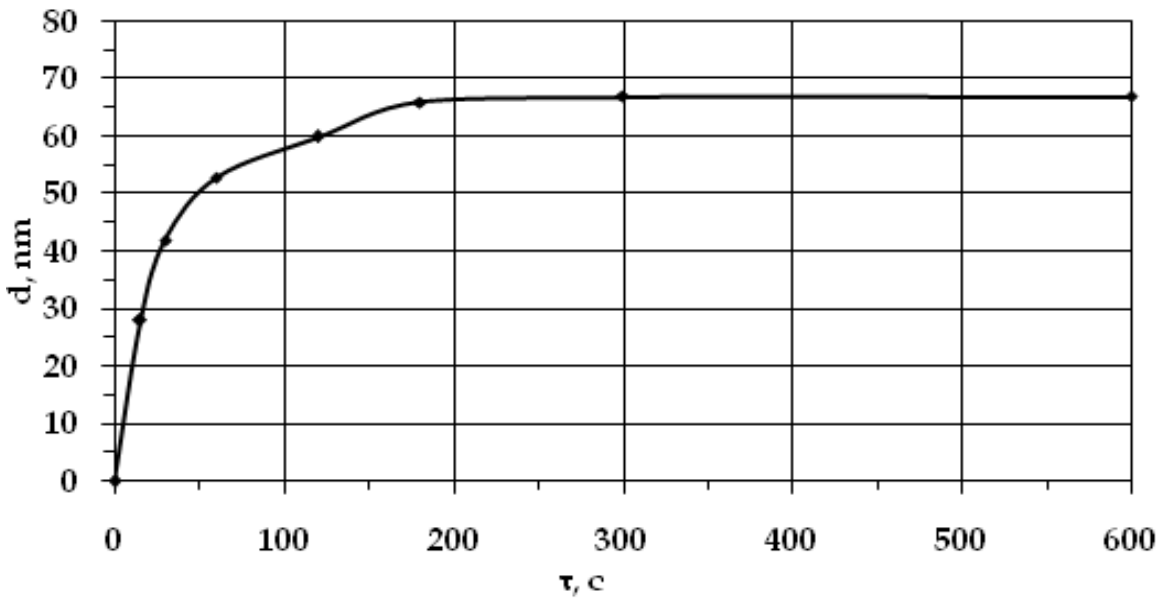

Fig.-3: Effect of Time of the Oxide-Zirconium Coating Deposition on the Thickness of Obtained Layers 
From the obtained experimental data the coating thickness increases with time for 3 minutes and is stabilized at a value of $65-67 \mathrm{~nm}$.

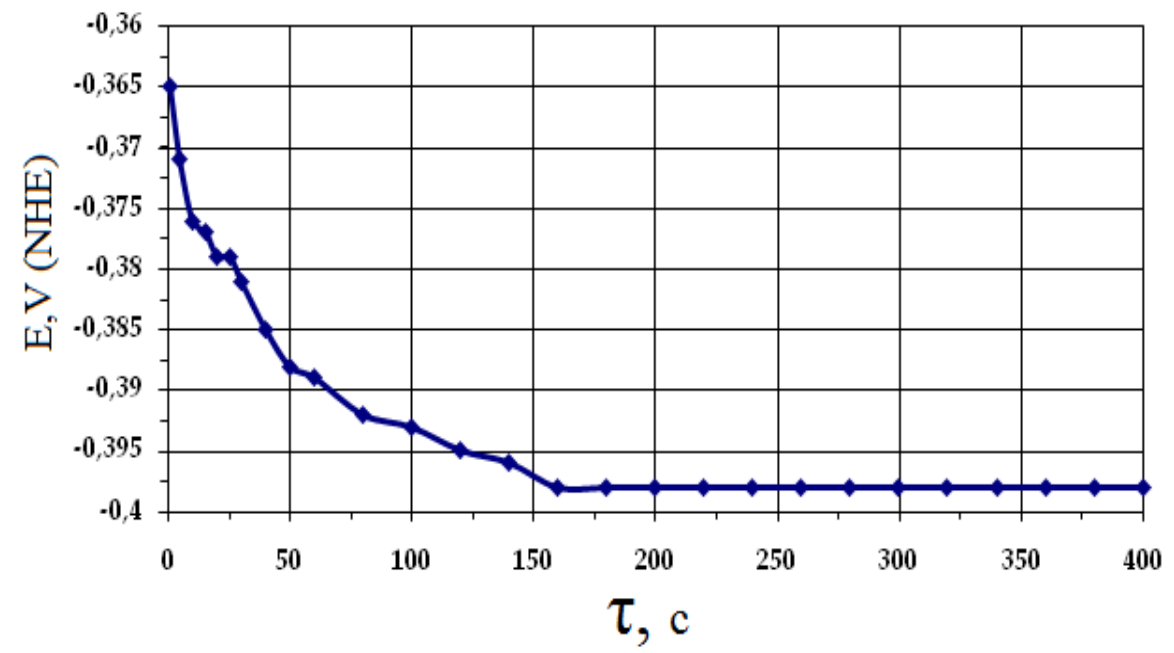

Fig.-4: Change of Current-Free Potential in the Process of Oxide-Zirconium Coatings Deposition

It should also be noted that the value of the current-free potential reaches a practically constant potential within 150-180 s. (Fig.-4).Experimentally established time characteristics indicate that the formation of zirconium oxide coatings on a steel base is completed within 3 minutes. This duration of the deposition time was chosen as a technological parameter.

The influence of the solution temperature on the thickness of the formed zirconium oxide coating was established. In Fig.-5 show the change of the coating thickness from its deposition temperature.

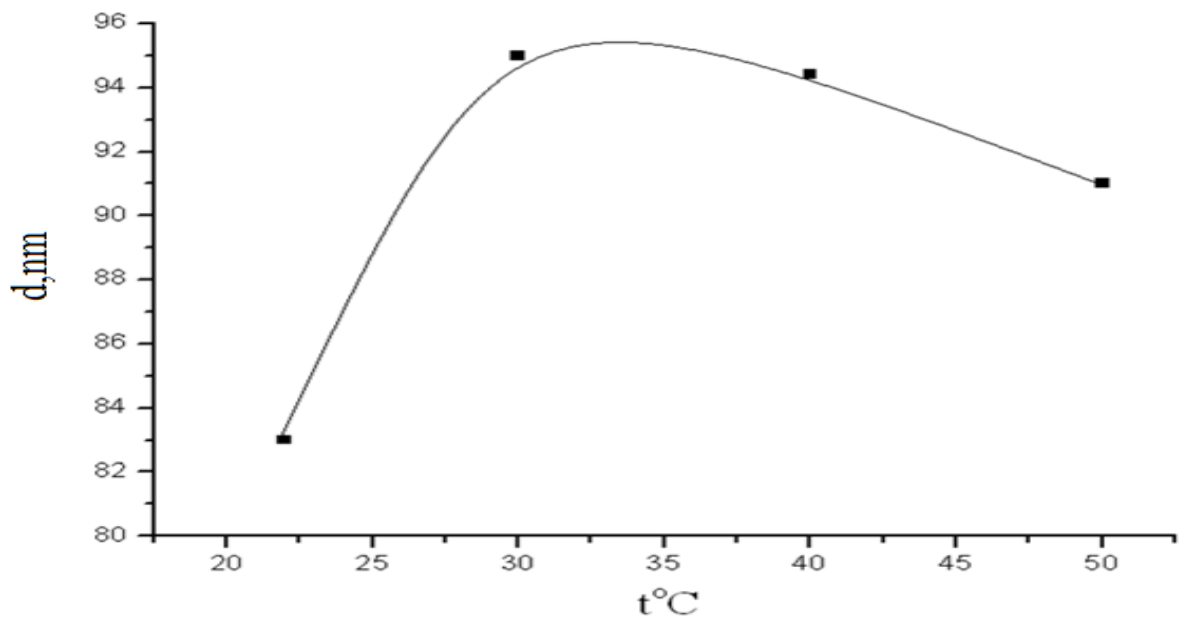

Fig.-5: Effect of Solution Temperature on the Thickness of the Oxide-Zirconium Coating

According to Fig.-5 with an increase in the deposition temperature, the coating thickness increases, reaching a maximum value at a temperature of $30-35^{\circ} \mathrm{C}$. A further increase in temperature leads to a decrease in the corrosion resistance of the formed coating. A great influence on the formation of oxidezirconium coatings and their corrosion resistance has the subsequent drying of the samples under study. In Fig.- 6 show the dependence of the oxide-zirconium coatings corrosion resistance on the temperature of the subsequent drying.

According to Fig.-6 maximum protective ability of zirconium oxide coatings is achieved at the subsequent drying temperature $130^{\circ} \mathrm{C}$ within $20 \mathrm{~min}$. At higher drying temperature their protective ability decreases. Adhesive strength is an important factor that characterizes the possibility of the obtained coatings using. Evaluation of the adhesion strength of the coating with a metal base was determined by 


\section{RASĀYAN $J$. Chem.}

Vol. 12 | No. 3 |1287 - 1293| July - September | 2019

the method of normal separation (the method of fungi) using an adhesiometer, which is based on measuring the minimum breaking stress required to separate the coating in the direction perpendicular to the metal base surface. The dependence of the oxide-zirconium coating adhesive strength on the temperature of its deposition is shown in Fig. - 7.

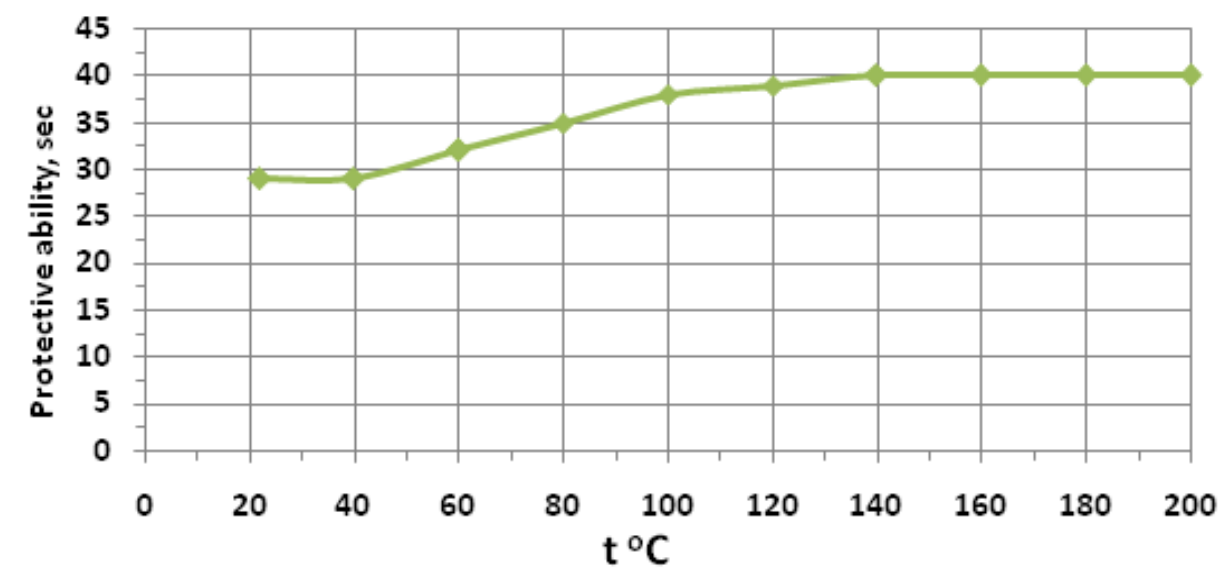

Fig.-6: Effect of the Subsequent Drying Temperature of the Samples with Zirconium Oxide Coatings on their Corrosion Resistance

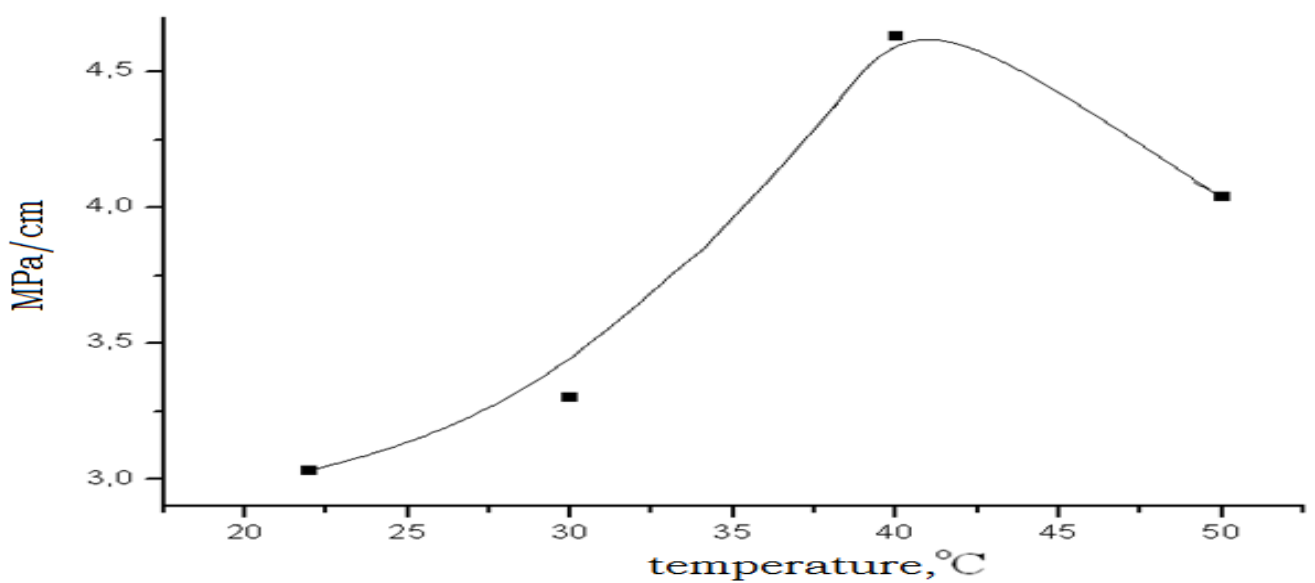

Fig.-7: Effect of Deposition Temperature of Oxide-Zirconium Coatings on their Adhesive Strength

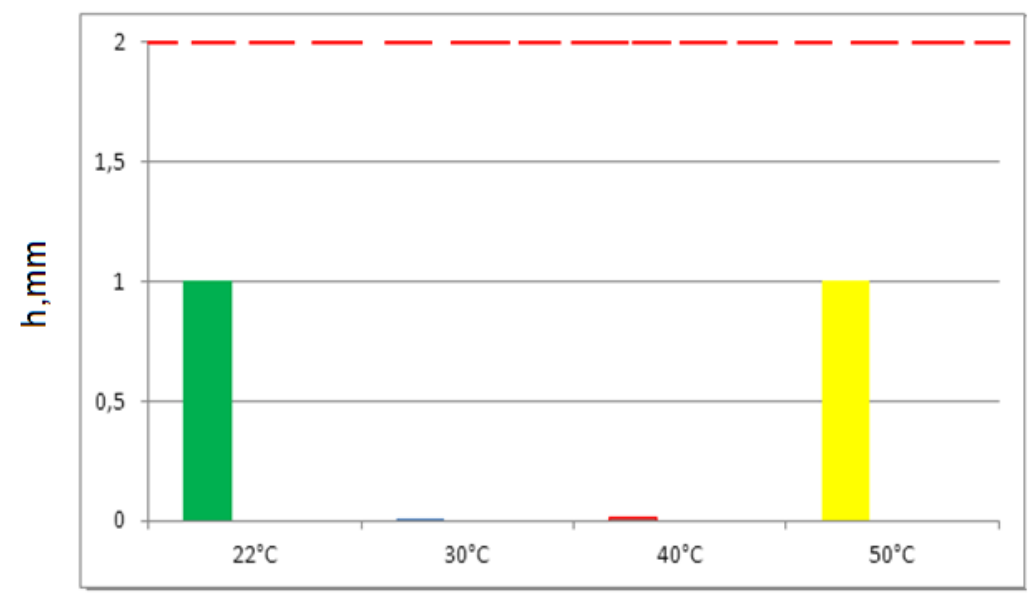

$\mathrm{t}^{\circ} \mathrm{C}$

Fig.-8: The Dependence of Oxide-Zirconium Coatings with Paint Corrosion Penetration (h) at Different Temperatures 
According to Fig.-7 the adhesive strength of oxide-zirconium coatings reach a maximum value at a deposition temperature of $40^{\circ} \mathrm{C}$ and is $4.63 \mathrm{MPa} / \mathrm{cm}$.

Corrosion tests on steel samples with an oxide-zirconium coating and paint were carried out in a salt fog chamber. The test samples were painted with a cruciform incision to the metal substrate of $0.5 \mathrm{~mm}$ in width. Samples of oxide-zirconium coatings after testing in the salt fog chamber at different temperatures are shown in Fig.-8.

According to Fig.- 8, the depth of corrosion penetration in cuts of steel samples with oxide-zirconium coatings obtained at $22^{\circ} \mathrm{C}$ and $50^{\circ} \mathrm{C}$ is $1 \mathrm{~mm}$; at $30^{\circ} \mathrm{C}$ and $40^{\circ} \mathrm{C}$, this value is almost 0 . Thus, testing in the salt fog chamber indicates that the optimum deposition temperature of the zirconium oxide coatings, at which a maximum corrosion resistance observed, is $30-40^{\circ} \mathrm{C}$, which is in agreement with the results of the coatings adhesive strength determination.

\section{CONCLUSION}

On the basis of the conducted studies, the optimal conditions for the formation of oxide-zirconium coatings on a steel base from a solution of hexafluorozirconic acid in the presence of Co (II) and Ni (II) ions were determined. Corrosion tests to determine the protective ability of the coatings obtained by the Akimov's method and in the salt fog chamber, depending on changes in process parameters were carried out. It is shown that the results of corrosion tests are in agreement with the adhesion strength of the obtained oxide-zirconium coatings on an iron base in the temperature range $30-40^{\circ} \mathrm{C}$.

\section{ACKNOWLEDGMENT}

The work was conducted under research grand project of AP05132222 "Development of resource-saving technology for applying ceramic adhesive nanocoatings with improved characteristics" and it was supported by D.I. Mendeleev University of Chemical Technology of Russia under a research grand project of 016-2018. The authors would like to place on record their sincere gratitude to the Ministry of Science and Education of the Republic of Kazakhstan for financial support.

\section{REFERENCES}

1. A.A. Abrashov, N.S. Grigoryan, T.A. Vagramyan and D.Yu. Zhilenko, Non-ferrous Metals, 11, 33(2016).

2. N.S. Grigoryan, E.F. Akimova and T.A. Vagramyan, Phosphating, Globus, Moscow, p.144, (2008).

3. A.A. Abrashov, N.S. Grigoryan, T.A. Vagramyan and E.F. Akimova, Electroplating and Surface Treatment, 18 (3), 48 (2010).

4. N.V. Kulyushina, N.S. Grigoryan, D.V. Mazurova, A.A. Kalinkina, V.V. Men'shikov and T.A. Vagramyan, Protection of Metals and Physical Chemistry of Surfaces, 47(7), 884 (2011).

5. A.A. Abrashov, N.S. Grigoryan, T.A. Vagramyan, R.V. Papirov and M.I. Styazhkina, Electroplating and Surface Treatment, 21(4), 40(2013).

6. A.A. Abrashov, N.N. Chamashkina, G.A. Yur eva, N.S. Grigoryan and T.A. Vagramyan, Electroplating and Surface Treatment, 20(4), 7(2012).

7. A.A. Abrashov, N.S. Grigoryan, T.A. Vagramyan, RU Patent 2622076 C1 (2017).

8. A.A. Abrashov, N.S. Grigoryan, G.A. Nazarova, L.O. Solod and T.A. Vagramyan, Science and World. International Scientific Journal, 1(11), 65 (2015).

9. T. Metroke, O. Kachurina and E. Knobbe, JCT Coat. Technol., 74, 927(2002).

10. B. Dunham, D. Chalk, L. Sharonville and M. Ohio, Cleaning, Pretreatment \& Surface Preparation, 5, 112(2012).

11. K.A. Saikat Adhikaria, Y. Unocica, G.S. Zhaia, J. Frankela and W. Zimmerman, Electrochemica Acta., 56, 1912 (2011), DOI: 10.1016/j.electacta.2010.07.037.

12. A. Ghanbari and M.M. Attar, Surface \& Coatings Technology, 246, 26(2014), DOI: 10.1016/j.surfcoat.2014.02.057.

13. H.E. Mohammadloo, A. A. Sarabi, A. S. Alvani, H. Sameiea and R. Salim, Surf. Coat. Technol., 206, 4132(2012), DOI: 10.1016/j.surfcoat.2012.04.009. 


\section{RASĀYAN J. Chem.}

Vol. 12 | No. 3 |1287 - 1293| July - September | 2019

14. AiHua Yi, WenFang Li, JunDuandSong Lin Mu, App. Surf. Science, 258, 5960(2012), DOI: 10.1016/j.apsusc.2011.12.045.

15. B. Tepe and B. Gunay, Progress in Organic Coatings, 62, 134(2008), DOI: 10.1016/porgcoat.2007.10.004.

16. GOST 9.302-88. Edinaya sistema zashchity ot korrozii i stareniya. Pokrytiya metallicheskie i nemetallicheskie neorganicheskie, Metodykontrolya, Moscow: Izdatel'stvo standartov, 40(1990).

17. ASTM B117 - 11. Standard Practice for Operating Salt Spray (Fog) Apparatus, 12 (2011).

[RJC-5205/2019] 